\title{
Abortion in Medical School Curricula
}

\author{
Atsuko Koyama*, MD, MPH, Robin Williams, MD
}

Studies show that in a group of five women- your mother, sister, aunt, daughter, girlfriend- two of them will have an abortion by age forty-four (1). Although this statistic varies by several factors including race and marital status, abortion is one of the most commonly performed surgical procedures in the United States and Canada $(1,2)$.

Abortion is a safe, legal and common procedure, yet it is not routinely taught in medical schools $(3,4)$. In fact, there are no requirements that abortion be included in medical school curricula (5). Because it is so common, it is important for medical students to learn about abortion- the technical aspects of the different types of procedures, as well as the social, global and public health issues involved in abortion provision. Regardless of an individual physician's personal beliefs about abortion, every physician has a responsibility to help patients achieve optimal mental and physical health, to inform patients of their reproductive health options, and to serve as patient advocates. Only through comprehensive education and training will future physicians be able to meet the reproductive health needs of women.

\section{BACKGROUND: A GLOBAL PERSPECTIVE}

To understand the importance of abortion from a public health perspective, one need only look at abortion incidence and maternal morbidity and mortality. Unintended pregnancies account for $40 \%$ of pregnancies in the developing world and 50 to $60 \%$ in the United States and Eastern Europe (6). Globally, more than a quarter of women who become pregnant either have an abortion or an unwanted birth (7). Recent statistics show that in the U.S. and Canada, 2 to 3 out of

* To whom correspondence should be addressed: Atsuko Koyama, 1135 Pelham Pkwy N \#1G, Bronx, NY 10469. Tel: 718-547-5536.

Email: akoyama47@yahoo.com
10 pregnancies end in abortion, and up to $40 \%$ of women will have an abortion during their reproductive life (1, 2, 7-10). These figures demonstrate that many physicians and medical students who include women in their clinical practice will inevitably treat someone who has had an abortion.

Of the 46 million women who obtain abortions worldwide, 20 million of them obtain illegal abortions, resulting in 70,000 deaths per year (7, 10). Maternal mortality rates from abortion in developing countries are estimated to average 330 deaths per 100,000 abortions, with the rate in Africa approaching 700 deaths per 100,000 abortions, a rate hundreds of times higher than that of developed countries (7).

The high mortality rates from abortions seen in developing countries are unheard of in developed countries such as the U.S. and Canada where abortion is legal $(7,11)$. When abortion is provided by trained medical professionals, it is one of the safest surgical procedures $(2,10)$. In the United States, the death rate from abortions is less than 0.6 per 100,000 procedures $(7,12)$. Although deaths caused by abortions are rare in the U.S. and Canada, it is important for medical students to learn about the effects of illegal abortions in order to appreciate the importance of safe, legal abortions to maternal health. As Dr. Mildred S. Hanson, an abortion provider who began providing before Roe v. Wade, said,

\footnotetext{
"We have to let young women and men know the tragedy and the horror of illegal abortion...And young doctors especially must realize what it was like when abortion was illegal" (13).
}

\section{THE LEGALITY OF ABORTION}

Not every pregnancy is planned, and as shown by the high maternal mortality rates in countries where abortion is illegal (7), access to safe, legal abortion is a key component to women's health. In the United States, 
in 1973, the Supreme Court recognized for the first time that the constitutional right to privacy "is broad enough to encompass a woman's decision whether or not to terminate her pregnancy," providing the possibility of safe, legal abortions for American women (14). In Canada, the right to safe, legal abortion was recognized by the Supreme Court of Canada in 1988 in the Morgentaler decision (15). In this landmark case, the abortion law requiring the approval of a therapeutic abortion committee before allowing women to have an abortion was struck down as it violated a woman's right to life, liberty and security of the person (15).

The rates of safe abortions substantially increase with the legalization of abortion, and the complication and death rates from abortion decrease, yet the overall rates of abortion do not substantially change simply because abortion is legal $(7,11)$. This suggests that the reasons women have abortions are not affected by the legality or safety of abortion, but rather, by the life circumstances of the woman.

While this situation is alarming, a recent UK authority (which provides some guidance in Australia) considers the proposition that the duty of confidentiality of a medical practitioner or researcher will not be breached where commercial use is made of deidentified (anonomised) data without the consent of the source of that information. The UK Court of Appeal held that anonomised information can be sold to commercial third parties without liability provided that the personal privacy of the information is protected.

\section{WHO HAS ABORTIONS}

In 2000, U.S. women of all ages, races, socioeconomic status and marital status had abortions (16). The highest rates were among women who were unmarried, poor, black or Hispanic, or aged 18-29 (16). Forty-three percent of women who have had an abortion identified themselves as Protestant, and $27 \%$ as Catholic (16). Sixty-one percent of women had previously had one or more births (16). Abortion rates were inversely proportional to income level (16).

The reasons women have abortions are many and complex, and they are similar worldwide $(6,7)$. The timing of births, the desire to control family size, socioeconomic reasons, relationship problems, age, marital status, maternal health, and fetal defects are all reasons women give for having an abortion $(6,7)$.

\section{ACCESS TO ABORTION SERVICES IN CANADA AND THE U.S.}

In spite of the legality of abortion in the U.S. and Canada, many women continue to lack access to abortion services. Two factors in particular- the declining number of abortion providers and a change in the distribution of abortion facilities- have significant adverse consequences for women's health, particularly for poor and rural women $(17,18)$. In Canada, only $17.8 \%$ of hospitals provide the service, and some provinces have no provider (17). Similarly, in the United States, in $2000,87 \%$ of counties had no provider (18).

A variety of factors have contributed to the decline in the number of providers. They range from physicians' personal moral objections to fears of becoming targets of violence or harassment (19-26). In addition, certain laws in the U.S. targeting abortion providers create barriers, while physician-only laws restrict other medical personnel such as nurse practitioners from providing abortions $(27,28)$. Abortion education in medical schools and residency programs is limited, which has been shown in several studies to decrease the likelihood of physicians choosing to provide abortions $(25,26,29,30)$. Lastly, Catholic hospital mergers have contributed to the lack of training opportunities while also decreasing the number of facilities offering abortion services (31-33).

The effect of the decrease in the total number of abortion providers is compounded by a related trend: a decrease in the number of hospital- based abortion services. Data from 1998 and 2000 in the U.S. show an $18 \%$ and $14 \%$ loss, respectively, in the number of hospitals providing abortions $(18,34)$. Although hospital abortions constitute only $5 \%$ of total abortions performed (18), this decrease disproportionately affects poor and rural women, who rely most heavily on hospital emergency rooms for medical care and who must travel great distances to obtain abortion services $(8,17,18)$. In addition, abortions performed in clinics are not always covered by Medicaid in the US or Medicare in Canada $(17,18)$. The decrease in hospital abortions also negatively affects the education of medical students and residents, who receive the majority of their training in hospital settings $(17,18$, $35)$.

\section{ABORTION IN MEDICAL SCHOOL CURRICULA: THE REALITY}

As $48 \%$ of women aged $30-34$ in the U.S. have experienced an unintended pregnancy, and 4 out of 10 women seek abortion services sometime during their reproductive life, the lack of abortion education in medical curricula significantly affects medical students' ability to address women's reproductive needs (1).

Espey et al. (2005) (3) surveyed Obstetrics and Gynecology clerkship directors to determine the extent of abortion education in U.S. medical schools. They found that $17 \%$ of schools had no abortion education at 
all and that in many other schools, coverage was minimal (3). One organization, Medical Students for Choice (MSFC), is currently surveying medical schools in the U.S. and Canada about their individual curricula. The preliminary results of MSFC's study of the reproductive health content of preclinical medical education found that nearly $40 \%$ of the more than 50 schools surveyed do not teach any aspect of abortion in the preclinical years (4). Indeed, the study found that, on average, more class time is dedicated to Viagra than to abortion procedures, pregnancy options counseling, or abortion law and policy (4). This glimpse into U.S. and Canadian medical curricula reveals that abortion is not a standard component of preclinical education.

\section{ABORTION IN MEDICAL SCHOOL CURRICULA: THE GOAL}

The teaching of abortion in medical schools and residencies is supported by numerous professional organizations, such as the American Medical Women's Association (AMWA) and other international health and human rights organizations (10, 36-39). Abortion education in medical school curricula should include descriptions of the different methods and procedures of medical and surgical abortions, as well as pregnancy options counseling, contraception, and a more global view of abortion, such as abortion from a human rights prospective and the effects of unsafe abortions on maternal health. If abortion were taught in this way, graduating medical students would understand not just the how of abortion, but the why, resulting in more compassionate care (2). This will also help to destigmatize the procedure, possibly encouraging medical students to become future providers.

There are many resources available for teaching pregnancy options counseling and contraception. Anne Baker's "Abortion and Options Counseling: A Comprehensive Reference" and the American College of Obstetricians and Gynecologists' "Pregnancy Choices: Raising the Baby, Adoption and Abortion" are excellent resources for discussing pregnancy options in the classroom $(40,41)$. For discussing contraception, Family Health International provides a slide set called, "Contraceptive Technology Expert." (42) The slide set covers topics such as injectables, lactational amenorrhea, postpartum contraception, and intrauterine devices and includes teaching modules with narrative, slides, audience handouts, references and reprints of scientific articles (42). Lastly, for students and professors interested in improving reproductive health education or developing a comprehensive reproductive health elective, the AMWA Reproductive Health Model Curriculum is an excellent resource (43).

In discussing abortion beyond the technical and individual aspects and expanding the discussion into abortion and comprehensive reproductive health as a human right, The Society of Obstetricians and Gynecologists of Canada sets out recommendations on how physicians can put reproductive health in a human rights perspective (36). A recommendation pertinent to medical education is that ethical and human rights principles be addressed early in medical training (36). Topics of discussion could include how stereotypical gender roles, power imbalances between men and women, cultural standards and the level of women's empowerment in society are linked to women's reproductive health (36).

\section{CONCLUSION}

Abortion, as one component of comprehensive reproductive health care education, should be a standard part of medical school curricula. The public health reasons for providing safe abortions, the number of women seeking the procedure, and the human rights implications involved, all contribute to making abortion an essential part of medical school curricula. If your school is not teaching you what you need to know to provide women with comprehensive medical care, here are some suggestions for how you can make a difference.

Actions to take: ask questions about medical abortion in pharmacology, pregnancy options counseling in behavioral science, and abortion procedures during your obstetrics and gynecology clinical rotation. Get involved in curriculum committees, support your local providers and professors who are including abortion in their curricula, and encourage your peers and faculty to talk about the myriad of issues around reproductive health. Most importantly, find your like-minded peers and work together to create change and make a difference in your schools.

\section{REFERENCES}

1. Henshaw S. Unintended pregnancy in the United States. Family Planning Perspectives 30(1): 24-29+46; 1998.

2. Stewart F, Darney P. Abortion: Teaching why as well as how. Perspectives on Sexual and Reproductive Health 35(1): 37-39; 2003.

3. Espey E, Ogburn T, Chavez A, Qualls C, Leyba M. Abortion education in medical schools: A national survey. American Journal of Obstetrics and Gynecology 192: 640-643; 2005.

4. Medical Students for Choice. Curriculum Mapping Project at the Leadership Training Program. Chicago, IL: MSFC, 2003.

5. Liaison Committee on Medical Education. LCME Accreditation Standards. http://www.lcme.org/pubs.htm. Accessed on January 8, 2004. Last updated on October 15, 2003.

6. Bankole A, Singh S, Haas T. Reasons why women have induced abortions: Evidence from 27 countries. International Family Planning Perspectives 24(3): 117-127 \& 152; 1998.

7. Sharing responsibility: Women, society and abortion worldwide. Alan Guttmacher Institute, 1999. 
8. Henshaw S. Factors hindering access to abortion services. Family Planning Perspectives 27(2): 54-59+87; 1995.

9. Statistics Canada and Canadian Institute for Health Information, Statistics Canada. http://www.statcan.ca/english/Pgdb/health42d.htm. Accessed on January 7, 2004. Last updated on March 23, 2003.

10. Safe abortion: Technical and policy guidance for health systems. World Health Organization, 2003.

11. Cates W, Grimes DA, Schulz K. The public health impact of legal abortion: 30 years later. Perspectives on Sexual and Reproductive Health 35(1): 25-28; 2003.

12. Unsafe abortion: Global and regional estimates of incidence of a mortality due to unsafe abortion with a listing of available country data - Third edition. World Health Organization, 1997.

13. Pelletreau E. Reflections of a provider before and since Roe: From the voices of choice archive. Perspectives on Sexual and Reproductive Health 35(1): 34-36; 2003.

14. Roe v. Wade. (1973). 410 U.S. 113

15. Morgentaler v. The Queen. (1988). S.C.J. No 1

16. Jones R, Darroch J, Henshaw S. Patterns in the socioeconomic characteristics of women obtaining abortions in 2000-2001. Perspectives on Sexual and Reproductive Health 34(5): p. 226$235 ; 2002$.

17. Protecting abortion rights in Canada. Canadian Abortion Rights Action League, 2003.

18. Finer L, Henshaw S. Abortion incidence and services in the United States in 2000. Perspectives on Sexual and Reproductive Health 35(1): 6-15; 2003.

19. 2001 year-end analysis of trends of violence and disruption against reproductive health care clinics. National Abortion Federation, 2001.

20. Dobie S, et al. Reproductive health services in rural Washington State: Scope of practice and provision of medical abortions, 1996-1997. American Journal of Public Health 90(4): 624-626; 2000.

21. Epstein D. Will violence end patients' access to abortion? Medical Economics 76(9): 51-54, 57-58, 61-63; 1999.

22. Fried M. Abortion in the US: barriers to access. Reproductive Health Matters 5(9): 37-45; 1997.

23. Meyers C, Woods R. An obligation to provide abortion services: What happens when physicians refuse? Journal of Medical Ethics 22(2): 115-120; 1996.

24. Rosenblatt R, Mattis R, Hart L. Abortions in rural Idaho: physicians' attitudes and practices. American Journal of Public Health 85(10): 1423; 1995.

25. Steinauer JE, DePineres T, Robert AM, Westfall J, Darney P. Training family practice residents in abortion and other reproductive health care: a nationwide survey. Family Planning Perspectives 29(5): 222-7; 1997.

26. Weisman CS, Nathanson CA, Teitelbaum MA, Chase GA, King TM. Abortion attitudes and performance among male and female obstetrician-gynecologists. Family Planning Perspectives 18(2): 67-73; 1986.
27. Lieberman D, Lalwani A. Physician-only and physician assistant statutes: A case of perceived but unfounded conflict. Journal of American Medical Women's Association 49(9): 146$149 ; 1994$.

28. Who decides? A state-by-state review of abortion and reproductive rights. National Abortion Rights Action League, 2002.

29. Aiyer AN, Ruiz G, Steinman A, Ho GY. Influence of physician attitudes on willingness to perform abortion. Obstetrics \& Gynecology 93(4): 576-80; 1999.

30. Westhoff C. Abortion training in residency programs. Journal of American Medical Women's Association 49(5): 150-154; 1994.

31. The facts about Catholic health care. Catholics for a Free Choice, 2002.

32. Bellandi D. Access declines; reproductive services fall with hospital consolidation. Modern Healthcare 28(16): 26; 1998.

33. Gallagher J. Religious freedom, reproductive healthcare, and hospital mergers. Journal of American Medical Women's Association 52(2): 65-68; 1997.

34. Henshaw S. Abortion incidence and services in the United States, 1995-1996. Family Planning Perspectives 30(6): 263270,287; 1998.

35. Grimes DA. Clinicians who provide abortions: The thinning ranks. Obstetrics \& Gynecology 80(4): 719-723; 1992.

36. Merali I. Improving reproductive and sexual health: Integrating women's empowerment and reproductive rights. Ottawa, ON: The Society of Obstetricians and Gynecologists of Canada, 2001.

37. Report of the International conference on Population and Development. Cairo, Egypt: United Nations, 1995.

38. Key actions for the further implementation of the Programme of Action of the International Conference on Population and Development. New York, NY: United Nations, 1999.

39. American Medical Women's Association. Resolution: Abortion.

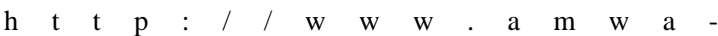
doc.org/publications/Resolutions/abortion.htm. Accessed on January 10, 2004.

40. Baker A. Abortion and Options Counseling: A Comprehensive Reference. Grainte City, IL: The Hope Clinic for Women, Ltd. 1995.

41. American College of Obstetricians and Gynecologists. Pregnancy choices: Raising the baby, adoption and abortion. Washington, DC: ACOG, 1993.

42. Contraceptive Technology Expert. Family Health International: (919) 544-7040.

43. American Medical Women's Association. AMWA: Reproductive Health Initiative. http://www.amwadoc.org/Education/RHI/outline.htm. Accessed on January 11, 2004.

Atsuko Koyama is a second-year pediatric resident at Jacobi Medical Center in Bronx, New York with plans to become an adolescent provider. She served on the Board of Medical Students for Choice for three years and is currently on the Board of Physicians for Reproductive Choice and Health. She received her MD from the University of Arizona, College of Medicine and MPH from the University of California at Berkeley.

Robin Williams graduated from Queen's University School of Medicine in May 2005. She has been involved with Medical Students for Choice throughout medical school as a School Coordinator, Regional Coordinator for Canada, and finally the National Coordinator for Canada in her last year. 